\title{
Exploration of Application of Humanistic Service Concept in Library Reader Service
}

\author{
Zhengyan Li \\ Sichuan University of Arts and Science, Dazhou, 635000, China
}

Keywords: Library, Reader Service, Humanistic service concept, Application, Exploration

\begin{abstract}
Library humanistic service concept of mainly stresses to manifest the status of readers, and the main service principle is reader-centered. In library reader service, humanistic service concept is important foundation of service mode reform and innovation, so it is required to highlight humanistic service concept in reader service process. This is also an important direction of library service concept. Therefore, this paper overall studies library humanistic service concept and expounds concrete applications of humanistic service concept in reader service of library.
\end{abstract}

\section{Introduction}

In recent years, the society ruled by law has formed gradually, so class division among people starts to disappear. Besides, equality has become a normal relation among people. Thus, people also enjoy non-violation of individual rights while equally performing obligations. Hence, "people first" idea gradually receives attention. In current library reader service, the specific service mode innovates and pays more attention to readers' humanistic care. In addition, readers' humanistic service concept is implemented in actual work. Meanwhile, its application in library service in different links fully reflects care, respect and understanding of readers. With the development of science and technology, the forms of information carriers become increasing rich so that readers' demand increases continuously. Thus, the library has certain pressure and challenges. So, to provide readers with better library service, it is required to follow the service concept based on humanistic service, and it is necessary to rationally innovate and reform library service concept.

\section{Overview of library humanistic service concept}

Library humanistic service concept is to fully manifest readers' subject status in actual library service and implement manifest service principle. In the process of implementing human-centered humanistic service concept, the following four aspects need to be stressed:

Firstly, Readers. Librarianship belongs to cultural education cause. Thus, once a library loses readers, it will lose the significance of existence. So, library employees have the obligation to strive for readers, love readers and respect readers and regard reader work as the key point of all library work.[1] Thus, in library services, readers are the subjects and also the objects of service activities.

Secondly, library service environment. Library service environment mainly includes humanistic environment and natural environment. Natural environment is internal condition of library and position selection, while humanistic environment is the relationship between library and society, i.e. so-called public relation. Hence, it is believed that library service activity consists of physical environment and interpersonal relationship environment. Besides, the two will form compound system environment. Simply speaking, physical environment and interpersonal relationship environment may serve as the foundation of library service activity environment. In the meantime, compound system environment has direct influence on readers' mood, mentality and library employees. The combination of factors influencing library employees and readers mood will form library service environment.

Thirdly, cultural background of library. From modern perspective, cultural background of library is spiritual wealth which forms in actual service activity in different library service links under current social conditions and background.[2] 
Fourthly, value of library. The attribute of things or phenomena is value. Usually, the value is purpose ad positive effect. However, value consciousness is also called value concept. Specifically, it refers to people's values pr faith for objective things and forms in long-term common life. Thus, modern library value is the concept and faith generalized by library in the process of pursuing high-quality service.

\section{Analysis of application necessity of humanistic service concept in library reader service}

\section{Main impetus of library service reform and innovation is humanistic service concept}

In library service reform and innovation, the main object is reader, and it is necessary to continuously meet readers' demand. Seeing from library humanistic service concept, it is required to depend on library employees to excavate and give play to the potential so as to drive reform and innovation of library service and better provide necessary conditions for readers' increasing spiritual culture demand.

\section{Starting point and ending point of library service activity reform and innovation are humanistic service concept}

The most active factor in productivity is human. In library service activity, employees are the most important productivity, and the ultimate aim of their work is to meet readers' increasing spiritual demand. Thus, the subjects of library humanistic service activity are readers, and become the decisive force of library reform and innovation. To make humanistic service concept in library service actively implemented, it is necessary to maintain readers' rights and interests, pay attention to readers' response, meet readers' demand and respect readers. Besides, starting point and ending point of humanistic service concept are put on readers' increasing spiritual culture demand. ${ }^{[3]}$

\section{Fundamental requirement of scientific development of library is humanistic service concept}

Library employees need to seek truth from facts, actively liberate thought, start from actual conditions, always stick to humanistic service concept, then make service concept innovative, form favorable service atmosphere and better attract readers.

\section{Application of humanistic service concept in library reader service}

\section{Library environment}

In terms of the appearance, the library needs to make readers keep cheerful mood, cheerful, give readers sense of art beauty and make readers generate spiritual and visual sense of beauty. Hence, the library with the sense of art beauty will certainly bring readers driving force and make readers walk in the library.

As is well-known, the library may serve as the palace of study and it is also knowledge bank. Hence, in terms of interior decoration of library, humanistic spirit must be reflected. Firstly, the humanistic spirits of world famous writers or ideologists are placed in the proper place in the library. Secondly, in library lighting design, human culture concept should be blended in it. Thirdly, the air in the library should be suitable, and the library should be clean and tidy to bring readers conformable feeling. Fourthly, the library still needs to offer convenient book borrowing system for readers, and set up corresponding small reading rooms. In this way, the feeling of study may be created for readers so that they may read books more comfortably.

\section{Circulation service of library}

Library humanistic service mainly includes purchasing management, circulation management and circulation service etc. Current library circulation concept mainly covers the following: 
Firstly, the library should not just set corresponding posts in the library and offer services for readers and other work, but also needs to arrange mobile service posts in order to better offer services for readers.

Secondly, library employees need to fully utilize advanced information technology. For example, email may be applied to remind or inform readers of specific borrowing deadline so that readers will not forget.

Thirdly, the library needs provide the latest book information for readers, and then readers may know book information in time and read books in time. ${ }^{[4]}$

Fourthly, the library needs to collect readers' opinions and purchase books in allusion to the opinions and suggestions. In this way, readers' demand can be better met.

\section{Library reading service}

In current stage, readers have higher and higher requirements for library reading service. So, original reading service cannot well meet readers' demand. Therefore, it is necessary to actively establish humanistic service concept of reading room and make service content and mode innovative.

Regard readers as the center and establish active service consciousness

In order to better adapt social development, contemporary library must keep up with the trend of the times, break through original concept, actively change service mode, advance with the times and establish new service concept of contemporary library. Hence, library employees should regard readers as the center, actively change service concept in ideology and establish active service awareness.

\section{Actively carry out reader-centered consultation service}

The main job content of traditional reading room employees is to organize document literature to make document literature more complete. Besides, they need to bind organized document literature. So, employees gradually generate the sense of boredom and consider they have no sense of achievement and sense of belonging in this job. Therefore, it is very hard to access and evaluate their work. Similarly, reading room service mode needs to reform and innovate. Usually, library employees are very familiar with the contents and quality of document literature in reading room. To change service mode, the most important work is to take full advantage of employees' advantages to offer corresponding consultation service for readers. Such method can give full play to advantages of library employees, boost their work enthusiasm and make them feel the sense of achievement. Meanwhile, such method can save readers' time to search document literature. It kills two birds with one stone.

Regard readers as the center and establish correct book procurement concept

In traditional sense, the work of reading room employees is to manage and organize routine periodicals and materials. So, they do not involve document literature booking and purchasing. But, readers gather in the reading room, and the flow of readers is very large and dense. Hence, it is necessary to deeply study readers' opinions and their reading demand so as to better offer favorable conditions and valuable information for book procurement.

\section{Social activity of library}

The library needs to take active part in various social activities and actively publicize its resources and services so as to better offer services for readers.

Firstly, the library should take active part in social activities for public good so as to effectively boost its popularity, establish good image and cultivate potential readers. Meanwhile, the library can advocate readers to engage in public benefit activities, better service the public and improve readers' moral sentiments.

Secondly, the library should organize humanistic knowledge activity at regular intervals and correctly guide readers. For example, the library may better attract readers through free academic and knowledge lectures. In addition, knowledge contest may be carried out for readers. The library may reward the readers with excellent performance in order to effectively boost readers' participation interest. 
Thirdly, the library still needs to make the best of modern media resources and then publicize library's advantages. For instance, official website of library may be applied to show the latest book information and library characteristics so that readers can more comprehensively know book information.

Fourthly, the library may let readers write and create readers' newspaper which is free for readers. Such method can make readers know the library,

\section{Reflection of humanistic service concept in library-reader interactive mechanism}

The quality of library service is only evaluated through the performance of employees, which cannot offer better services for readers. ${ }^{[5]}$ So, the library needs to establish readers' evaluation platform in allusion to service problems. Then, library service content and mode can be perfected and improved through readers' opinions and suggestions in order to offer more superior services for readers. But, in the process of constructing evaluation platform, it is necessary to pay attention to the convenience and usability of platform. Simply speaking, platform design needs to fully take into account of readers with different cultural levels so that readers can better use the evaluation platform to feed back opinions. Secondly, the platform needs to be open. Thus, in platform design process, log-in condition should not be limited to local area network of library, but external network client needed to be opened. This contributes to readers' opinion feedback. The final problem is security degree of evaluation platform. The security degree needs to make sure library employees cannot distinguish readers' real identity during collecting feedback opinions to achieve real anonymity feedback and better gather readers' real ideas.

\section{Conclusions}

In conclusion, in contemporary library reader service, humanistic service concept runs through it. This not just fully reflects library concept, but also can correct guide readers' service work. Thus, it has certain practical significance. In library service work, readers are always the subjects. The work purpose of library employees is to serve readers. So, the library is reader-centered in environment construction and documental information supply, and its aim is humanistic service concept. Meanwhile, no matter how library service content changes and no matter how service mode improves, humanistic service concept is the fundamental starting point and ending point of service work reform and innovation. Therefore, library reader service will always manifest humanistic service concept. This paper analyzes humanistic service concept in contemporary library reader service, sets forth its important realistic function, mainly studies the application of humanistic service concept in library reader service, then offer valuable theoretical basis for library work and drives smooth implementation of library work.

\section{References}

[1] Dai Qiurong, Reflection of humanistic service concept in library reader service. Library Tribune, 2011,31(4):144-146.

[2] Tan Weiyi, Humanistic service concept in library reader service. Office Operation,2014(7):138.

[3] Shao Guiqiong, Reflection of humanistic service concept in library reader service. Youth Literator, 2013(23):241-241.

[4] Bai Xiaohong, Reflection of humanistic service concept in library reader service. Managerialist, 2012(19):366.

[5] Liu Xiaoqing, Liu Yu'e, Thought and practice of modern library reader service concept and mode - case study of library in Agricultural University of Hunan. Journal of Library and Information Sciences in Agriculture, 2015,27(5):162-164. 